\title{
Aluminum-doped Zinc Oxide Trench Hyperbolic Metamaterial as a Mid-infrared Sensing Platform
}

Shkondin, Evgeniy; Repän, Taavi; Lavrinenko, Andrei; Takayama, Osamu

Published in:

Optical Sensors 2018

Link to article, DOI:

10.1364/SENSORS.2018.SeW2E.5

Publication date:

2018

Document Version

Peer reviewed version

Link back to DTU Orbit

Citation $(A P A)$ :

Shkondin, E., Repän, T., Lavrinenko, A., \& Takayama, O. (2018). Aluminum-doped Zinc Oxide Trench Hyperbolic Metamaterial as a Mid-infrared Sensing Platform. In Optical Sensors 2018 Optical Society of America (OSA). https://doi.org/10.1364/SENSORS.2018.SeW2E.5

\section{General rights}

Copyright and moral rights for the publications made accessible in the public portal are retained by the authors and/or other copyright owners and it is a condition of accessing publications that users recognise and abide by the legal requirements associated with these rights.

- Users may download and print one copy of any publication from the public portal for the purpose of private study or research.

- You may not further distribute the material or use it for any profit-making activity or commercial gain

- You may freely distribute the URL identifying the publication in the public portal 


\title{
Aluminum-doped Zinc Oxide Trench Hyperbolic Metamaterial as a Mid-infrared Sensing Platform
}

\author{
Evgeniy Shkondin, Taavi Repän, Andrei V. Lavrinenko, Osamu Takayama \\ ADTU Fotonik - Department of Photonics Engineering, Technical University of Denmark, Ørsteds Plads 343, DK-2800 Kgs. Lyngby, Denmark \\ Authore-mail address: alav@fotonk.dtu.dk
}

\begin{abstract}
We demonstrate enhancement of infrared absorption of $5 \mathrm{~nm}$ thick silica layer in nanotrench structures that function as hyperbolic metamaterials. Such structures can serve as a highly sensitive platform for mid-infrared absorption spectroscopy. (C) 2018 The Author(s)
\end{abstract}

OCIS codes: (250.5403) Plasmonics; (160.4760) Optical properties; (160.3918) Metamaterials; (220.4241) Nanostructure fabrication; (280.4788) Optical sensing and sensors

The mid-infrared (IR) spectroscopy in the wavelengths region between $2.5-25 \mu \mathrm{m}\left(4000-400 \mathrm{~cm}^{-1}\right)$ is a powerful tool to detect molecules and chemical bonds due to their particular absorption bands in this range [1-3]. It enables a variety of potential applications from gas sensing for environmental monitoring to medical and clinical diagnoses. However, due to the huge mismatch between the mid-infrared light wavelength and analyte molecules dimensions, which are typically on the order of several nanometers, it is challenging to detect very trace amounts of molecules by detecting their absorption signatures.
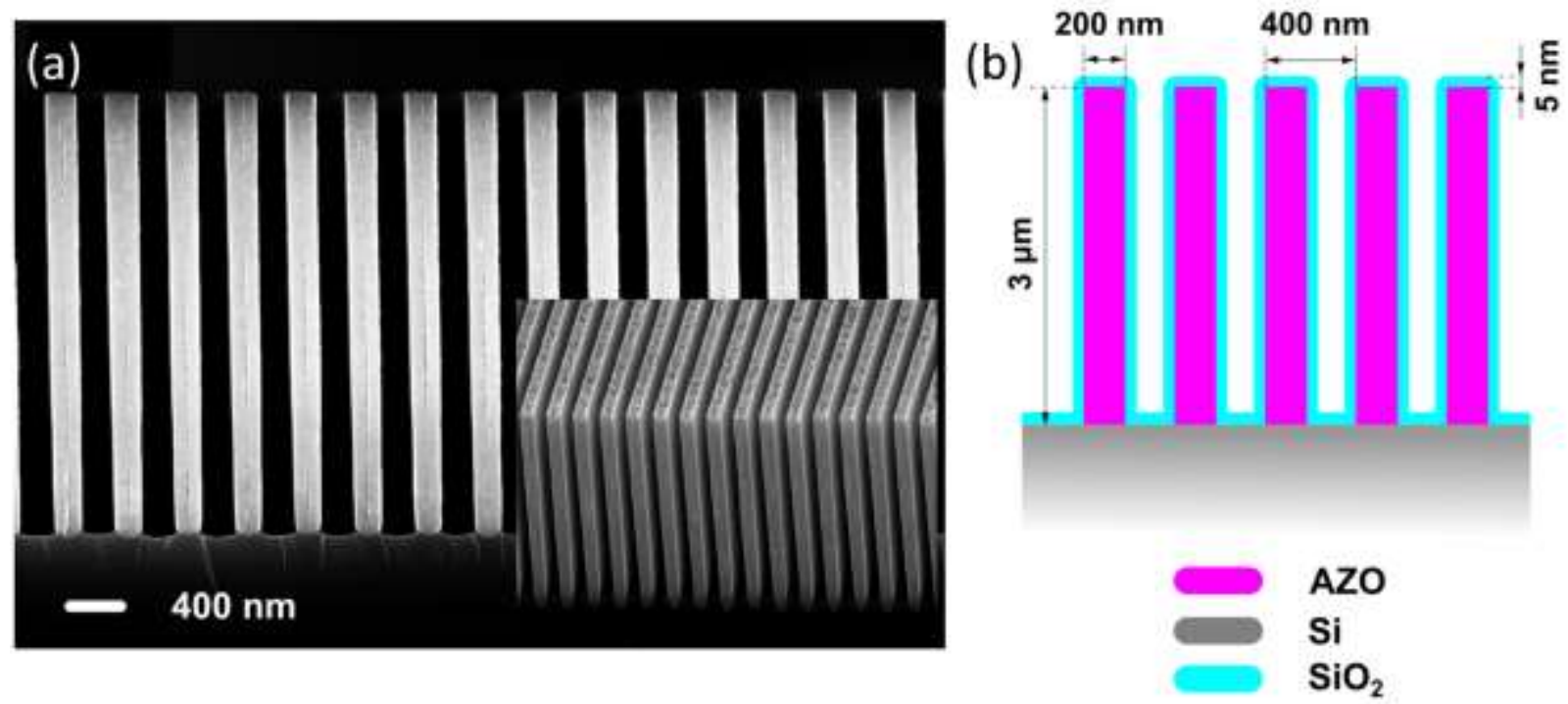

Fig. 1. (a) Cross-sectional SEM images of AZO-based HMM structures and bird's eye view of the structures. (b) A schematic illustrations of AZO trench structures with $5 \mathrm{~nm}$ thick $\mathrm{SiO}_{2}$.

Hereby we report the use of hyperbolic metamaterials (HMMs) based on aluminum-doped zinc oxide (AZO) nanotrench structures as a sensing platform for the enhancement of molecular absorption of mid-IR light. HMMs are artificially designed structures that possess unusual indefinite dispersion in a certain region of frequencies and exhibit the hyperbolic shape of the isofrequency contours in the wavevector space [4]. AZO exhibits a plasmonic response, possessing a negative real part of the permittivity in the near- and mid-IR wavelength regions [5-7].

The structures are composed of multiple high aspect ratio (1:6.7) sub-wavelength AZO trenches on a Si substrate, Fig.1(a), providing 14.5 times more surface area for residing of analyte molecules than the flat surface. The whole structure is fabricated by the combination of deep UV lithography, dry etching, and ALD technique for AZO deposition, resulting in the uniform formation of deep trenches on a large scale area $\left(2 \times 2 \mathrm{~cm}^{2}\right)$. The fabrication process for the trench structures is fully compatible with the large-scale CMOS technology. Such AZO trench HMM structures support both surface waves and bulk plasmon waves in the broad wavelength range in midIR [7]. 
Here we exploit the bulk plasmon waves for enhancement of mid-IR light absorption by molecules. In order to demonstrate the potential of the trench HMMs for sensing we coat the trench structure with a $5 \mathrm{~nm}$ thick $\mathrm{SiO}_{2}$ layer by ALD, emulating the presence of an analyte as illustrated in Fig. 1(b). $\mathrm{The}^{\mathrm{SiO}_{2}}$ layer exhibits strong phonon absorption around $8 \mu \mathrm{m}$ wavelength. As shown in Fig. 2(a), we measured free-space reflection of the samples with and without a $5 \mathrm{~nm} \mathrm{SiO}$ layer in the mid-IR wavelength range of $6.25-10 \mu \mathrm{m}\left(1600-1000 \mathrm{~cm}^{-1}\right)$. The reflection difference yields over $9 \%$ as shown in Fig. 2(b) [8]. The enhanced absorption is achieved by the two factors: interaction of bulk plasmon modes propagating in the trenches with the analyte silica layer and profoundly extended surface area of the trench structure with the fixed footprint.

In conclusion, the AZO trench structure exhibits broadband HMM performance in the range of wavelengths important for molecular sensing. Moreover, the doping level of AZO can be changed to adjust its plasmonic properties for desired wavelengths, leading to the optimum sensitivity of molecules on demand. Our demonstration shows that such structures can be effectively designed to detect traces of a target analyte and molecular sensing in mid-IR spectroscopy.

This work was supported by Villum Fonden "DarkSILD project" (11116) and Direktør Ib Henriksens Fond, Denmark. The authors would like to acknowledge the support from the Danish National Center for Micro- and Nanofabrication (DTU Danchip).
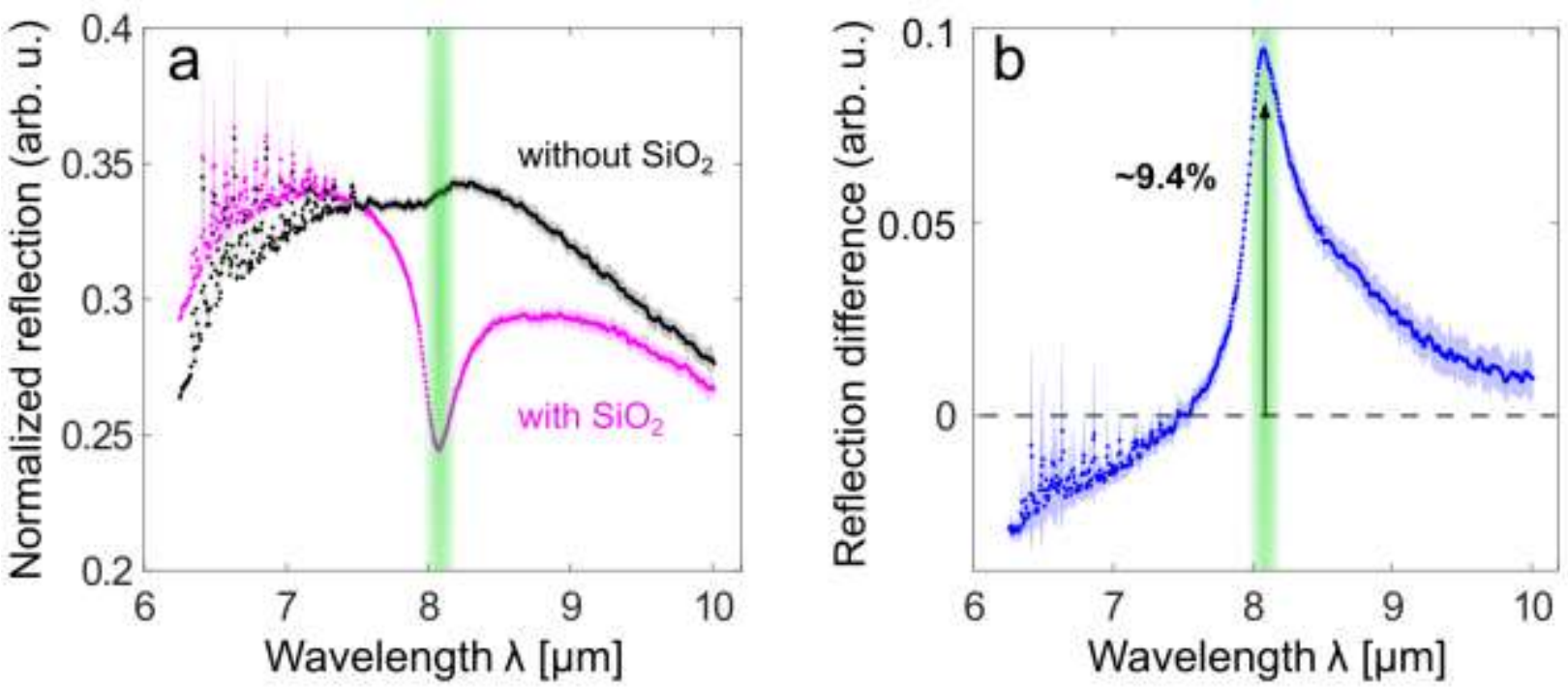

Fig. 2. (a) Measured free-space reflection of AZO trench structures with (dotted pink) and without (dotted black) $5 \mathrm{~nm}$ thick $\mathrm{SiO}_{2}$ layer. (b) Reflection difference. The angle of incidence is $\varphi=12^{\circ}$ with TM-polarized incidence light for all reflection measurement. Colored shade represents an error bar.

\section{References}

[1] S. Law, V. Podolskiy and D. Wasserman, "Towards nano-scale photonics with micro-scale photons: the opportunities and challenges of midinfrared plasmonics," Nanophotonics 2, 103-130 (2013).

[2] R. Adato, S. Aksu and H. Altug, "Engineering mid-infrared nanoantennas for surface enhanced infrared absorption spectroscopy," Mater. Today 18, 436-446 (2015).

[3] J. Haas and B. Mizaikoff, “Advances in Mid-Infrared Spectroscopy for Chemical Analysis,” Annu. Rev. Anal. Chem. 9, 45-68 (2016).

[4] A. Poddubny, I. Iorsh, P. Belov, and Y. Kivshar, "Hyperbolic metamaterials,” Nature Photon. 7, 948-957 (2013).

[5] G. V. Naik, V. M. Shalaev, and A. Boltasseva,.” Alternative plasmonic materials: Beyond gold and silver.” Adv. Mater. 25, 3264-3294 (2013).

[6] E. Shkondin, O. Takayama, M. E. A. Panah, P. Liu, P. V. Larsen, M. D. Mar, F. Jensen, and A. V. Lavrinenko, "Large-scale high aspect ratio Al-doped ZnO nanopillars arrays as anisotropic metamaterials," Opt. Mater. Express 7, 1606-1627 (2017).

[7] O. Takayama, E. Shkondin, A. Bogdanov, M. E. A. Panah, K. Golenitskii, P. Dmitriev, T. Repän, R. Malureanu, P. Belov, F. Jensen, A. V. Lavrinenko, "Midinfrared surface waves on a high aspect ratio nanotrench platform.," ACS Photonics 4, 2899-2907 (2017).

[8] E. Shkondin, T. Repän, M. Esmail Aryaee Panah, A. V. Lavrinenko and T. Takayama "High aspect ratio plasmonic nanotrench structures with large active surface area for label-free midinfrared molecular absorption sensing," ACS Appl. Nano. Mater., accepted (2018). 